about two-thirds of an acre and yielded within six months from the time of sowing the seed 97 pounds of seed. With the exception of what was turned over to the United States Department of Agriculture, all this is being used in increase work to secure larger stocks to distribute. This climate seems to be particularly favorable to the natural production of alfalfa seed on stocks that are acclimated."

"I also put out thirty acres of alfalfa in rows in 1907, sowing one to two pounds to the acre in drills two and one-half feet apart. These stocks were South Dakota Nos. 162, 164, 167, and 240. These are all being grown for seed to distribute in a commercial way. They are not pedigreed stocks in the true sense of the term, but are stocks that have given good records at the Experiment Stations in this State."

\title{
REPORT OF THE COMMITTEE ON BREEDING COTTON.
}

Dr. D. N. Shozmaker, Washington, D. C., Chairman.

W. A. Orton, Washington, D. C. Prof. C. L. Newman, Raleigh, N. C. Prof. D. A. Saunders, Waco, Texas
Prof. R. J. H. DeLonch, Experiment, Ga. Prof. S. M. BaIn, Knoxville, Tenn.

Prof. J. F. Duggar, Auburn, Ala.

Objects-To investigate and report on methods and technique of breeding cotton for various purposes, localities, and conditions; to encourage the production of improved purebred varieties of cotton for each agricultural region, and possibly for each soil in the cotton belt, and for each purpose.

(Report submitted by the Chairman.)

The committee has held no meetings, but the Chairman has heard from the various members. The main part of the report consists of special papers by Prof. R. J. H. De Loach and the Chairman, with a contribution by Mr. H. A. Allard.

The last year has seen considerable progress in the various cotton breeding problems in the country. The place of greatest interest at present is in Louisiana and Mississippi, where weevil injury has been extreme this year. It seems that the old long staple varieties will have to be given up in the presence of the weevil. Professor D. A. Saunders, of the U. S. Department of Agriculture, has been at work for three years on a cross between Sunflower and Triumph at Shreveport, Louisiana. This variety in the trial plots at this place has proven itself more productive each year than the old long staple varieties. A small amount of this is being distributed this year under the name of Foster.

The work in breeding early Upland cottons for Tennessee has resulted 
in a new variety, which seems well adapted to western Tennessee conditions. This has been named Trice by Professor S. M: Bain.

Columbia cotton, a more productive long staple Upland, has continued to grow in favor in many parts of the eastern cotton-growing region. The question of marketing this grade of lint in the local short staple markets is the greatest problem in the introduction of this variety.

\section{A STUDY OF LEAF CHARACTERS IN COTTON HYBRIDS.}

By D. N. Shommaker, Department of Agriculture, Washington, D. C.

The leaf of the Upland cotton grown in the United States is palmate with from three to five rather shallow sinuses. That of Sea Island and Egyptian cottons is more deeply cleft, and certain Mexican cottons have their leaves reduced to very narrow lobes, usually five. Many of the Asiatic species have leaves in which the indentations are intermediate between the last two instances cited. In each group, however, the leaf type is fairly constant. Many Upland varieties have individual leaf characters, and most of the Upland long staple varieties have slightly deeper sinuses than the short staple types. Garden okra, Hibiscus esculentus, shows very great variability in its leaf forms, which go through as great a range as is found among the cottons.

Several varieties of Upland short staple cotton show a few plants of a type usually known among planters as "okra cotton." This type has been disseminated as a variety in the past, but has been found to have only limited value. The writer has found this type in fairly well selected fields of Jones' Improved, Shine, and King. It is more common in King than in the others, however. When breeding work was begun in Texas in the attempt to find varieties of cotton better adapted for culture in the weevil-infested region, an okra leafed type of King cotton was isolated. It was found to breed very true to type, and it would have been easy to multiply if it had shown signs of value, but it did not prove very productive.

In breeding cottons for various purposes, crosses have been made between strains, varieties, and frequently between species. These crosses have been very difficult to fix, especially where the relationship has not been close, as between Sea Island, or Egyptian, and Upland cotton. Very little has been published on the application of Mendel's law to cotton crosses. The variation in length of lint is so slight in most of the crosses made that it would hardly be possible to prove the application of Mendel's law to the lint character, though this is the most important 